\title{
Aplikasi Mobile Android E-Learning dan Kuesioner pada SMK Muhammadiyah 7 Jakarta
}

\author{
Tria Hadi Kusmanto \\ ${ }^{1}$ Informatika, Universitas Indraprasta, Jakarta, Indonesia \\ e-mail: 'triahadi226@gmail.com \\ Reviewed Date: January $13^{\text {th }}, 2021$ \\ Accepted Date: April 01 ${ }^{\text {st }}, 2021$
}

Submitted Date: December $22^{\text {nd }}, 2020$

Revised Date: March 30 $0^{\text {th }}, 2021$

\begin{abstract}
SMK Muhammadiyah 7 Jakarta already has many learning systems that are applied in learning activities. The use of ICT in learning activities such as the use of internet networks, projector devices, local computers and networks. Basically, this system is sufficient to assist the teaching and learning process and in conducting school research (questionnaire). Teaching and learning is a process of relations between teachers and students. The questionnaire is a data collection technique by giving written and unwritten questions to get answers from respondents. However, these activities have not been realized in their development, such as using an Android-based learning system and questionnaire. In accordance with this explanation, an application is needed to assist the teaching and learning process and school research (questionnaire). This research was conducted to realize the development of an android-based system.
\end{abstract}

Keywords: Android; Questionnaire; School; Muhammadiyah; Information Technology

Abstrak

SMK Muhammadiyah 7 Jakarta sudah memiliki banyak sistem pembelajaran yang di terapkan dalam kegiatan belajar. Penggunaan TIK dalam kegiatan pembelajaran seperti penggunaan jaringan internet, perangkat projector, lomputer local dan jaringan. Pada dasarnya sistem ini cukup membantu berjalannya proses belajar mengajar serta dalams melakukan riset sekolah (kuesioner). Belajar mengajar adalah suatu proses relasi antara guru dan siswa. Perangkat kuesioner merupakan teknik pengumpulan data dengan cara memberikan pertanyaan tertulis dan tidak tertulis untuk mendapatkan jawaban dari responden. Namun kegiatan tersebut belum terealisasi dalam pengembangannya seperti menggunakan sistem pembelajaran dan kuesioner berbasis android. Sesuai dengan penjelasan tersebut diperlukan suatu aplikasi untuk membantu proses belajar mengajar dan riset sekolah (kuesioner). Penelitian ini dilakukan untuk merealisasikan dalam pengembangan sistem berbasis android.

Kata kunci: Android; Kuesioner; Sekolah; Muhammadiyah; Teknologi Informasi

\section{Pendahuluan}

Teknologi komunikasi saat kini banyak menciptakan inovasi dengan perangkat terbaru (Mustakini, 2009). Contoh teknologi berbasis mobile phone seperti telepon selular, smartphone atau ponsel cerdas dan komputer tablet. Komputer telah mendominasi di berbagai bidang kerja atau aktifitas untuk meningkatkan kemudahan, efektifas dan efesiensi sehingga memiliki peranan yang sangat penting (Taufiq, Magfiroh, Yusup, \& Yulianti, 2020).

Bidang pendidikan dalah salah satu kegiatan yang dapat menerapkan perkembangan teknologi informasi. Teknologi informasi ditujukan untuk membantu pekerjaan dengan menyediakan informasi dan melakukan berbagai tugas yang berhubungan dengan pengolahan informasi (Hanum \& Saifudin, 2019). Dunia pendidikan pada dasarnya adalah proses komunikasi dan transformasi informasi dari pendidik kepada siswa. Pendidikan menjadi sumber informasi yang menggunakan media sebagai sarana penyajian ide, gagasan dan materi pendidikan maka diperlukan sebuah aplikasi untuk pembelajaran agar menarik minat belajar bagi kalangan siswa/siswi dan masyarakat pada umumnya. 
SMK Muhammadiyah 7 Jakarta, yang beralamatkan di Jalan Tebet Timur Raya No. 565, Jakarta Selatan merupakan sekolah yang mempunyai beberapa kompetensi keahlian, dimana terbagi atas dua kompetensi yaitu Teknik Komputer Jaringan dan Manajemen Perkantoran. Semua jurusan di sekolah telah terakreditasi A sejak tahun 2009 dan menggunakan pembelajaran sistem KTSP.

SMK Muhammadiyah 7 Jakarta sudah memiliki banyak sistem pembelajaran yang di terapkan dalam kegiatan belajar. Penggunaan TIK dalam kegiatan pembelajaran seperti penggunaan jaringan internet, perangkat projector, lomputer local dan jaringan. Pada dasarnya sistem ini cukup membantu berjalannya proses belajar mengajar serta dalam melakukan riset sekolah (kuesioner). Belajar mengajar adalah suatu proses timbal balik yang terjadi antara guru dan siswa, sedangkan kuesioner merupakan teknik pengumpulan data dengan cara memberikan pertanyaan tertulis dan tidak tertulis untuk mendapatkan jawaban dari responden. Namun kegiatan tersebut belum terealisasi dalam pengembangannya seperti menggunakan sistem pembelajaran dan kuesioner berbasis android.

Android digunakan untuk dapat mengakses data secara wireless (teknologi nirkabel) dengan menggunakan perangkat mobile (ponsel, smartphone, tablet) yang tersambung pada sebuah jaringan telekomunikasi. Berdasarkan penjelasan tersebut diperlukan suatu aplikasi yang dapat membantu proses belajar mengajar dan riset sekolah (kuesioner). Penelitian ini dilakukan untuk merealisasikan dalam pengembangan sistem berbasis android.

\section{Analisa Masalah}

Beberapa pokok-pokok permasalahan dari hasil penelitian dan latar belakang yang ada dapat diidentifikasikan. Tenaga pengajar menggunakan metode konvensional dalam pembelajaran pada SMK Muhammadiyah 7 Jakarta. Variasi metode pembelajaran dapat membuat siswa tidak merasa bosan untuk diikuti. Tidak ada ragam model pembelajaran yang dilakukan oleh siswa diluar sekolah.

Dalam melakukan riset, sekolah masih menggunakan metode kuesioner konvensional. Kesulitan dalam memberikan nilai kuesioner dalam metode kuesioner konvensional.

Penelitian terbatas pada pengembangan media pembelajaran berupa E-Learning dan kuesioner berbasis Android di kelas XI SMK
Muhammadiyah 7 Jakarta. Aplikasi ini mencakup materi mengenai mata pelajaran sekolah kejuruan (Teknik Komputer Jaringan dan Manajemen Perkantoran) berdasarkan SAP dan kuesioner pada SMK Muhammadiyah 7 Jakarta.

Pembangunan aplikasi ini mencakup pengolahan data seperti masukan data guru, masukan data siswa, masukan data kelas, masukan data mata pelajaran secara otomatis, dan pembaharuan data guru, pembaharuan data siswa, pembaharuan data kelas, dan pembaharuan data mata pelajaran secara otomatis. Smartphone yang digunakan hanya yang menggunakan sistem operasi Android versi terendah yaitu JellyBean dan versi tertinggi yaitu Nougat. Editor yang digunakan dalam membuat aplikasi Android adalah Android Studio.

\section{Perancangan Sistem}

Aplikasi yang dibuat termasuk sebagai sistem infomasi. Informasi merupakan hasil pengolahan data sehingga menjadi bentuk yang penting bagi penerimanya dan mempunyai kegunaan dasar dalam pengambilan keputusan yang dirasakan akibatnya secara langsung saat itu juga atau secara tidak langsung pada saat mendatang (Edhy, 2011). Sedangkan sistem informasi adalah kumpulan dari sub-sub sistem yang saling terintegrasi dan berkolaborasi untuk menyelesaikan masalah tertentu dengan cara mengolah data sehingga memiliki nilai tambah dan bermanfaat bagi pengguna (Taufiq, 2018). Tujuan sistem informasi terdiri dari kegunaan (usefulness), ekonomi (economic), keandalan (realibility), pelayanan langganan (customer service), kesederhanaan (simplicity), dan fleksibilitas (fleksibility) (Mustakini, Analisis dan Desain Sistem Informasi, 2010).

Suatu aplikasi adalah program yang siap digunakan. Aplikasi komputer ini dirancang menjalankan fungsi untuk pengguna atau aplikasi lainnya (Kristanto, 2008). Banyak sekali contoh aplikasi seperti pengolah kata atau browser untuk membuka halaman web (Whardana, 2010).

Pengembangan sistem memerlukan metode agar proses pengembangan berjalan sesuai aturan baku (Sutabri, 2016). Metode pemodelan merupakan salah satu proses untuk membantu pengembagan sistem secara logika dalam bentuk contoh desain tiruan. Metode Prototyping (Nugroho, 2009) digunakan dalam penelitian ini untuk menggambarkan sistem yang dirancang pada SMK Muhammadiyah 7 Jakarta. SMK Muhammadiyah 7 Jakarta dapat melihat 
pemodelan sistem berupa tampilan sistem yang dibangun.

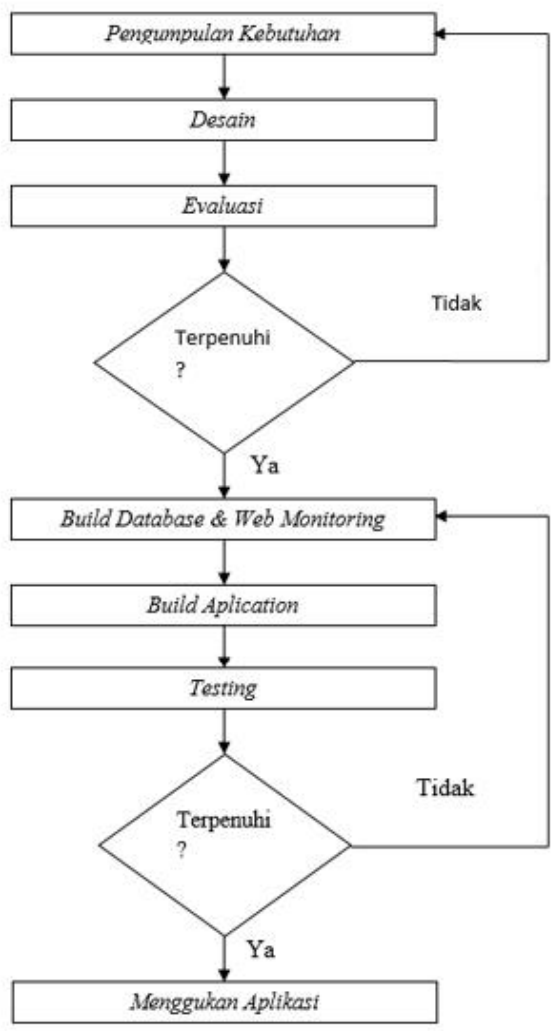

Gambar 1. Metode Prototype

Model perancangan sistem pada penelitian ini menampilkan Use Case Diagram, Activity Diagram, dan Class diagram yang disajikan sebagai berikut:

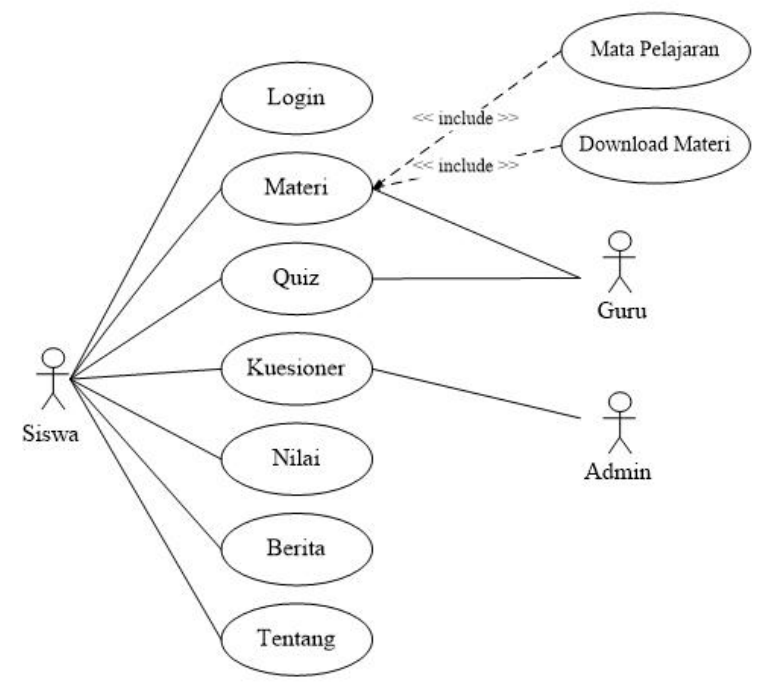

Gambar 2. UseCase Diagram
Pada gambar 2. Use Case Diagram aplikasi E-Learning dan Kuesioner menunjukkan fungsionalitas aplikasi dan menggambarkan bagaimana sistem tersebut berinteraksi dengan pengguna (Munawar, 2005).

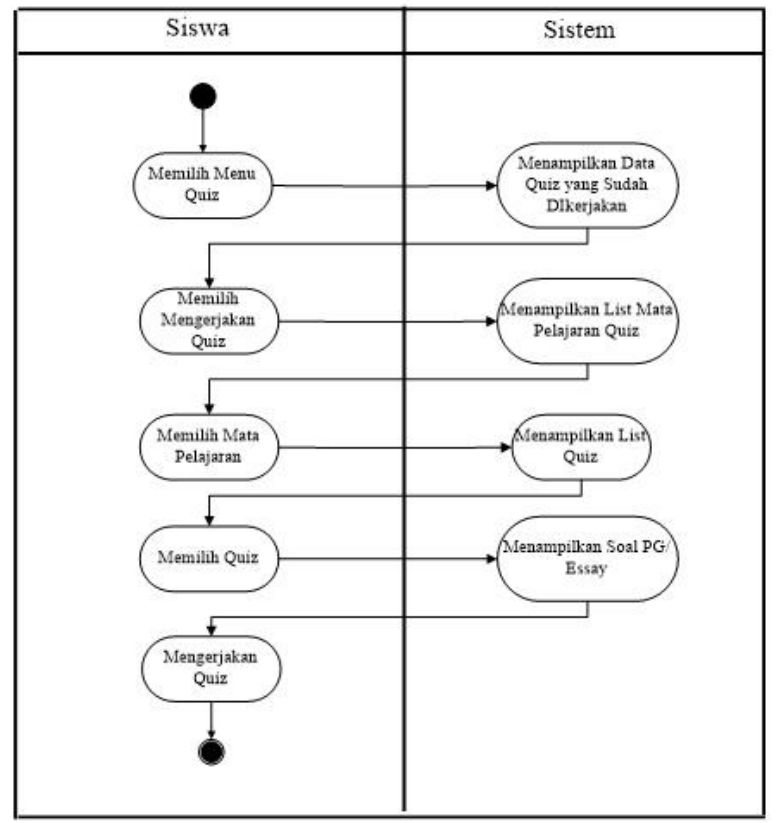

Gambar 3. Activity Diagram Aplikasi

Activity Diagram menampilkan alir awal aktivitas, decision yang mungkin terjadi, dan akhir dari aktivitas dan lebih menggambarkan prosesproses dan jalur-jalur aktivitas dari level atas secara umum.

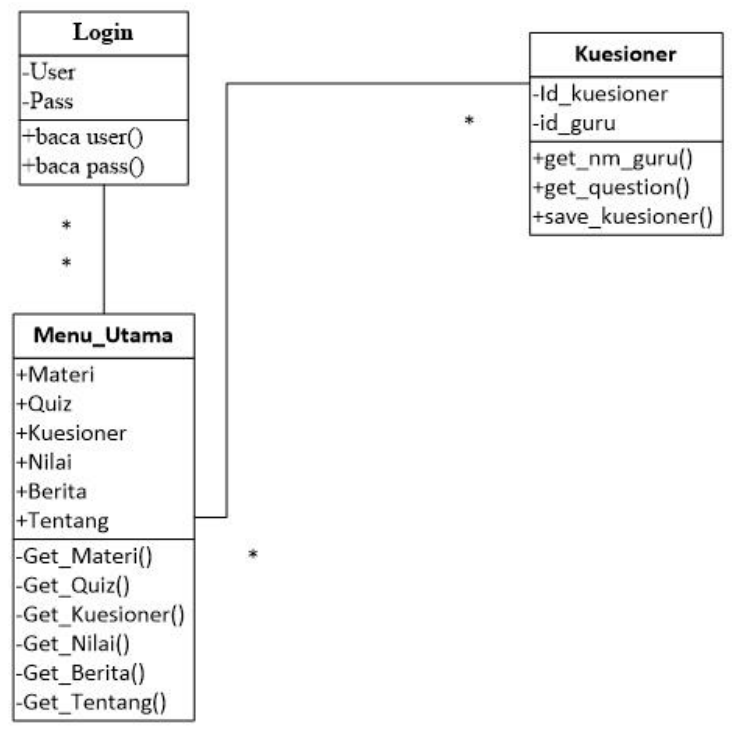

Gambar 4. Class Diagram Sistem 
Pada gambar 4 menggambarkan objek atau class dalam sistem yang mewakili elemen aplikasi. Objek dalam diagram ini memiliki atribut dan fungsi dan satu sama lain saling berinteraksi.

Sebelum diimplementasikan atau digunakan, aplikasi/sistem perlu dilakukan pengujian. Pengujian merupakan tahapan penting yang harus dilakukan untuk memberikan jaminan terhadap kualitas perangkat lunak yang dikembangkan (Muslimin, et al., 2020). Pengujian software sebenarnya memiliki tujuan utama yang sederhana, yaitu untuk menjamin software yang dihasilkan sesuai dengan kebutuhan (requirement) yang ditetapkan sebelumnya (Maulana, Kurniawan, Keumala, Sukma, \& Saifudin, 2020).

\section{Implementasi Sistem}

Masukan username dan password yang telah didaftarkan, klik "SIGN IN" untuk melanjutkan proses login.

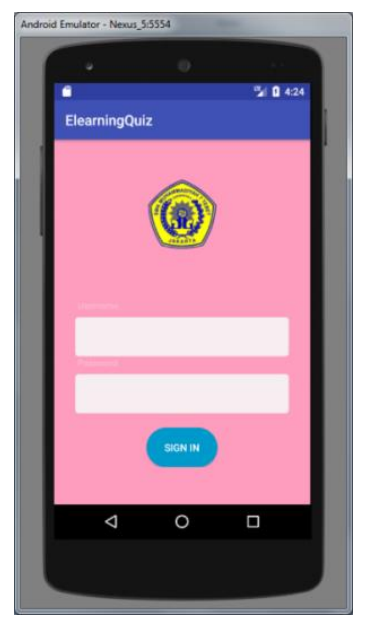

\section{Gambar 5. Mobile E-Learning}

Saat pertama kali aplikasi berjalan setelah diinstalasi, aplikasi akan meminta izin untuk mengakses kontak, media dan photo yang ada diperangkat. Pilih " $A L L O W$ " untuk menyetujui izin aplikasi.

\section{List Materi Download}

Tampilan ini berisi list materi download menyeluruh dari mata pelajaran, pilih untuk melanjutkan proses download.

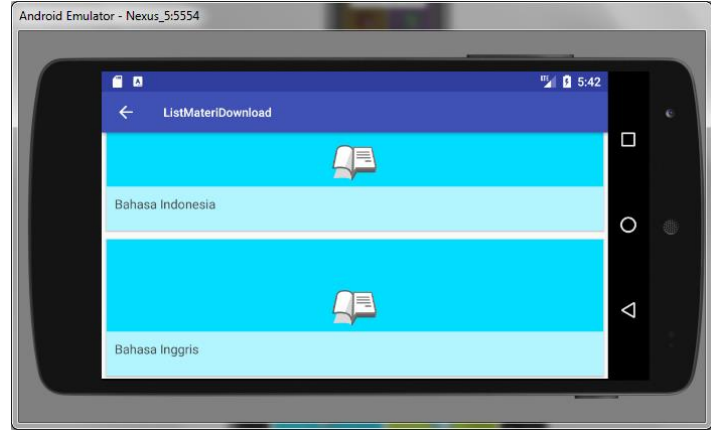

Gambar 6. List Materi Download

\section{Mata Pelajaran Quiz}

Tampilan ini berisi list Mata Pelajaran pada quiz, pilih untuk melanjutkan mengerjakan quiz.

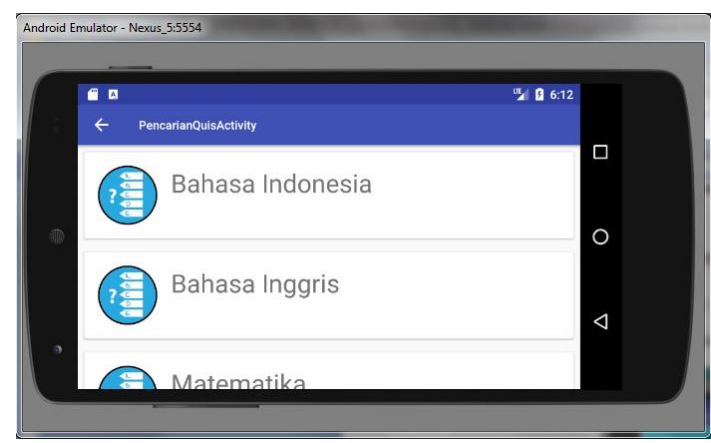

Gambar 7. Mata Pelajaran Quiz

\section{Form Pengerjaan Soal}

Tampilan ini berisi soal soal dari pilihan ganda maupun essay. Pada dashboard juga terdapat informasi waktu pengerjaan soal. Klik "Selesai" untuk mengirim soal yang dikerjakan.

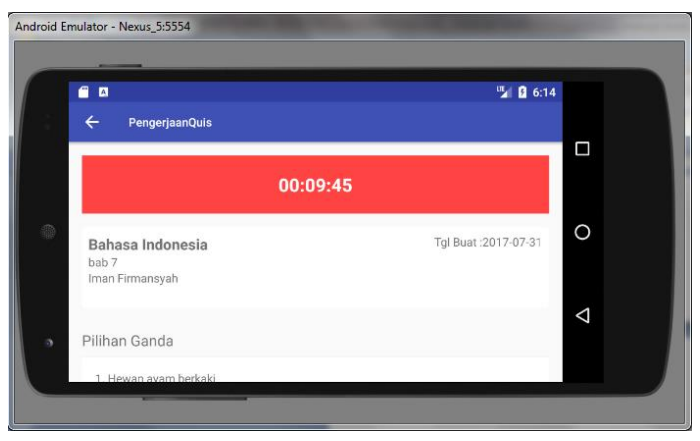

Gambar 8. Pengerjaan Soal Quiz

\section{Menu Nilai}

Setelah memilih menu "Nilai" tampil dashboard nilai, ini adalah tampilan yang berisi hasil quiz yang sudah dikerjakan. 


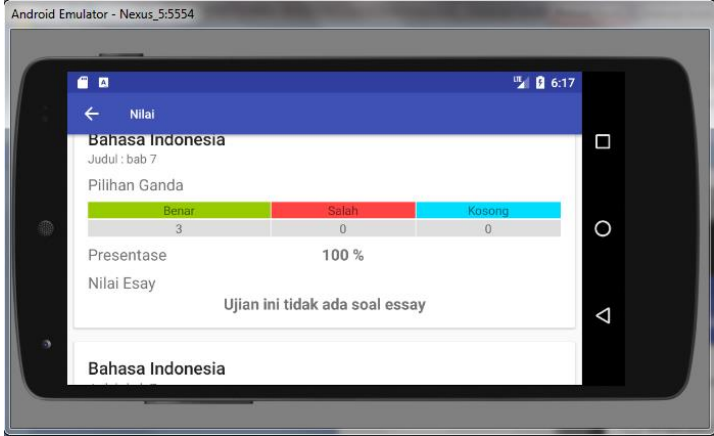

Gambar 9. Dashboard Nilai

\section{Menu Kuesioner}

Setelah memilih Menu "Kuesioner" muncul tampilan untuk mengisi kuisioner. Notifikasi "harap isi semua kuesioner" menandakan ada salah satu kuesioner belum diisi, klik "selesai" jika sudah mengisi kuesioner

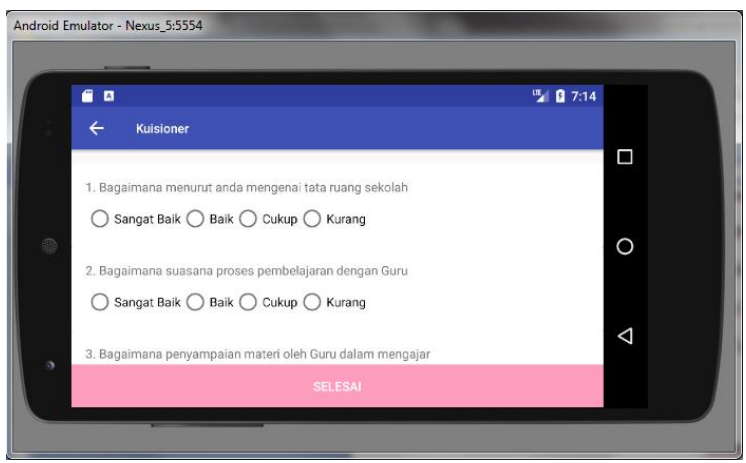

Gambar 10. Pengisian Kuesioner

Berdasarkan hasil ujicoba aplikasi ada informasi yang dapat menjelaskan kelebihan dan kekurangan dari aplikasi ini.

\section{Kelebihan:}

a. Penggunaan perangkat telepon pintar dapat membantu siswa mendapatakan pengetahuan tambahan dari internet. Informasi tersebut dapat berupa artikel, essay, diagram, dan bentuk informasi pengetahaun lainnya.

b. Pengajar dan siswa dapat menggunakan bahan ajar yang terstruktur dan terjadwal melalui internet.

c. Berubahnya peran siswa dari yang pasif menjadi aktif.

d. Akses menjadi lebih luas, bisa dimana saja.

e. Pengelolaan data tugas dan menjadi terkomputerisasi.

f. Pengelolaan data kuisioner dan hasil kuisoner terkomputerisasi.

\section{Kekurangan:}

a. Membutuhkan akses koneksi yang stabil dalam mengerjakan soal / tugas.

b. Pada program ini hanya bisa digunakan pada platform android.

c. Pada program ini siswa belum bisa melakukan registrasi untuk pendaftaran Mobile ELearning langsung pada aplikasi, pendaftaran hanya bisa dilakukan oleh pihak sekolah.

\section{Kesimpulan}

Dengan dibangunnya aplikasi E-Learning dan Kuesioner ini maka dapat ditarik beberapa kesimpulan, yaitu:

a. Dengan adanya sistem ini proses belajar mengajar menjadi lebih mudah dan dapat dilakukan pencatatan data untuk karyawan yang memakai kendaraan operasional.

b. Siswa dapat melakukan pembelajaran dimanapun dan kapanpun.

c. Dapat mempermudah dalam penilaian riset sekolah (kuesioner).

\section{Saran}

Pada penelitian ini ada beberapa tahapan yang belum selesai dikerjakan sehingga dapat memebrikan informasi tambahan kepada para peneliti lain seperti:

a. Aplikasi ini dapat dikembangkan sehingga saat siswa mendaftarkan akun e-learning dan kuesioner, admin tidak perlu melakukan pengecekan daftar siswa disekolah.

b. Aplikasi ini dapat dikembangkan agar tidak hanya dapat dipakai oleh siswa tapi juga dapat dipakai oleh guru/pengajar.

c. Aplikasi ini dapat dikembangkan kembali dalam hal design atau penambahan database sesuai kebutuhan e-learning dan kuesioner sekolah.

\section{Referensi}

Edhy, S. (2011). Sistem Informasi Manajemen. Yogyakarta: Andi Offset.

Hanum, W. S., \& Saifudin, A. (2019). Rancang Bangun Aplikasi Panduan Pariwisata di Kabupaten Banyuwangi Mobile Berbasis Android. Jurnal Teknologi Sistem Informasi dan Aplikasi, 2(2), 59-65. doi:10.32493/jtsi.v2i2.2798

Kristanto, A. ( 2008). Perancangan Sistem Informasi dan Aplikasinya. Bandung: Gava Media.

Maulana, A., Kurniawan, A., Keumala, W., Sukma, V. R., \& Saifudin, A. (2020). Pengujian Black Box pada Aplikasi Penjualan Berbasis Web 
Menggunakan Metode Equivalents Partitions (Studi Kasus: PT Arap Store). Jurnal Teknologi Sistem Informasi dan Aplikasi, 3(1), 50-56. doi:10.32493/jtsi.v3i1.4307

Munawar. (2005). Pemodelan Visual dengan UML. Yogyakarta: Graha Ilmu.

Muslimin, D. B., Kusmanto, D., Amilia, K. F., Ariffin, M. S., Mardiana, S., \& Yulianti, Y. (2020). Pengujian Black Box pada Aplikasi Sistem Informasi Akademik Menggunakan Teknik Equivalence Partitioning. Jurnal Informatika Universitas Pamulang, 5(1), 19-25. doi:10.32493/informatika.v5i1.3778

Mustakini, J. H. (2009). Sistem Teknologi Informasi. Yogyakarta: Andi Offset.

Mustakini, J. H. (2010). Analisis dan Desain Sistem Informasi. Yogyakarta: Andi Offset.

Nugroho, A. (2009). Rekayasa Perangkat Lunak Menggunakan UML dan Java. Yogyakarta: Andi Offset.
Sutabri, T. (2016). Sistem Informasi Manajemen. Yogyakarta: Andi Offset.

Taufiq, R. (2018). Pengantar Sistem Informasi. Jakarta: Mitra Wacana Media.

Taufiq, R., Magfiroh, D. A., Yusup, D., \& Yulianti, Y. (2020). Analisis dan Desain Sistem Informasi Pembayaran Sumbangan Pembinaan Pendidikan (SPP) di SMK Avicena Rajeg. Jurnal Teknologi Sistem Informasi dan Aplikasi, $\quad 3(1), \quad$ 15-21. doi:10.32493/jtsi.v3i1.4308

Whardana. (2010). Menjadi Master PHP dengan Framework Codeigniter. Elek Media Komputindo: Jakarta. 